leak-proof packaging and shipping papers to accompany waste). A petition for reconsideration of this rule has been filed by the American Hospital Association (AH\&). They believe the DOT regulations should be prevented from becoming effective as scheduled in October 1992 because they were promulgated without a public comment period in violation of the Administrative Procedure Act. The AHA petition is concerned that DOT

significantly expanded its existing scope (e.g., substituted EPA's definition of "regulated medical waste" with DOT's definition of "infectious substance" [etiologic agent]) without demonstrable benefit.

It is also likely that when the Resource Conservation and Recovery Act is reauthorized this year, there will be a medical waste component. The two bills that are currently being considered are S. 976 (Baucus) and S. 2108

(Durenberger). While both of these bills go beyond what is scientifically justifiable and impose needless excess costs, Senate bill 2108 is the more restrictive of the two bills and would expand the Medical Waste Tracking Act demonstration program to a national program.

William A. Rutala, PhD Chapel Hill, North Carolina

\title{
NIH Town Meeting
}

\section{Dr. Richard Garibaldi represented SHEA at the February 25, 1992, regional strategic planning session of the National Institutes of Health (NIH) that was held at the University of Connecticut. He filed the following report.}

This meeting was one of five regional meetings being held throughout the United States to rekindle the partnership between the NIH and the scientific community and to develop a strategic plan for the NIH that will extend into the next century. Participants at our Connecticut meeting included more than 500 individuals. The meeting was lively and interactive.

Subgroups discussed five specific, trans-NIH objectives that relate to specific operational policies, including the setting of priorities in critical science and technology; the targeting of our research enterprise to respond to current and emerging public health needs; the strengthening of our efforts to nurture and train new research talent; the establishment of an equitable system of management among the diversified basic and clinical research interests of the individual Institutes; and the maintenance of public respect, trust, and confidence in the scientific community. The entire group re-examined the NIH mission statement, its goals, and philosophy.

Despite the presence of an overwhelming preponderance of basic scientists, there was a strong endorsement of the NIH's role in bringing new biomedical knowledge to the bedside. The critical nature of clinical trials and epidemiologic research was acknowledged and emphasized. Virtually everyone accepted the premise that the competitive RO1 mechanism for investigator initiated research funding must remain the bedrock of NIH funding. However, there was strong sentiment to encourage and support the training of new, young investigators in all aspects of biomedical research. Even though there was a reluctance to endorse specific research or disease priorities, there was a strong feeling that the NIH's responsibility extended beyond the laboratory to epidemiologic applications in clinical practice.

Richard A. Garibaldi, MD Farmington, Connecticut

\section{SHEA Scientific Meeting-Boffo in Baltimore}

By all measures, the Annual Scientific Meeting in Baltimore, April 12-14, was extraordinarily successful. There were about 500 attendees-well above the projected 300-400. The exchange of uptothe-minute information was electrifying, and although the weather was excellent, every scientific session had standing- room-only crowds.

The annual business meeting was held in conjunction with the scientific meeting-rather than during the SHEA ICAAC luncheon-for the first time. (The luncheon will continue as an annual social and educational event.) At the business meeting, our secretary, Dr. William
Martone, reported that our membership is now over 600 -strong and that a new membership directory is being sent to all members (those at the meeting received advanced copies). Our treasurer, Dr. Elias Abrutyn, reported that we remain solvent. 